\title{
Practices on Over the Counter Medication among Mothers of Under Five Aged Children Attending Child OPD at Friends of Shanta Bhawan, Boudha, Kathmandu
}

\author{
Maharjan M \& Adhikari K
}

Nepal Institute of Health Sciences

\begin{abstract}
Background: Over the counter medicines are drugs that are brought without a medical prescription. The use of many OTC medicines in children is usually initiated by parents. Self medication in developing countries from a biological point of view point the risks that are involved in developing countries are reportedly higher than in industrialized countries. This can be related to the fact that in many developing countries drugs are available over the counter. In a study conducted in Pokhara, western Nepal found that $59 \%$ had taken self medication including OTC medicines.
\end{abstract}

Objective: To assess the practices on OTC drug among mothers of under five aged children

Methodology: The descriptive cross sectional study design was used. All the mothers of under five aged children visiting the Friends of Shanta Bhawan at the child OPD and had taken OTC medicines during last 6 months for child and wished to participate in the study were included using non probability purposive sampling technique during four weeks of data collection.

The data was collected from 100 samples by face to face interview technique using semi-structured questionnaire. Descriptive analysis such as mean, median, frequency, percentage, standard deviation was calculated according to the objectives.

Results: Most of the respondents (92\%) took OTC for fever, $75 \%$ took for cough and cold. $65 \%$ of respondents used OTC medicines because the pharmacy is near from their homes and $48 \%$ used it due too easy to get the medicine as compared to visit to doctors or hospital.

Conclusion: This study concluded that mothers used OTC for the common problems of their children because OTC medications are near to reach and easy to get than to visit to doctors or hospitals.

Key word: Over the counter, under five aged children

\section{INTRODUCTION}

Over the counter (OTC) medicines are drugs that are bought without a doctor's prescription. People around the world tend to treat the disease, almost $50 \%$ either wait for the problem to run its course or use a home remedy. About $25 \%$

visit a doctor or use a prescription medicine previously obtained for the same condition. The remaining $25 \%$ turn to the OTC medicines. ${ }^{1}$ The study in population of Czech Republic showed that, they OTC would buy just on the basis of television advertising by $7 \%$ of respondents. In case for one year child $8 \%$ respondents opted for OTC. ${ }^{2}$ In China, $70 \%$ of consumers select the OTC medicines through reading specification before purchase.

In a study carried out by student of Manipal College of Medical sciences done in Pokhara, Western Nepal found that $59 \%$ had taken self medication including OTC drugs. The common reasons given for self medication were mild illness, previous experience of treating a similar illness and non-availability of health personnel. ${ }^{3}$ Similarly a study conducted in a rural village in Philippines revealed that antibiotics are routinely given in self medication for non severe childhood diarrheal illness. ${ }^{4}$ A study carried out in Brazilian village found that $50-66 \%$ uses antibiotics as an OTC medication for the children..$^{5}$ Many OTC drugs have drug interaction with prescriptions and other drugs. In fact drugs which can aggravate certain medical condition. They can results to even death as well. More medicines does not necessarily mean better. However there is no adequate study regarding OTC in Nepal. So, this study aims to assess the practices on OTC drug among mothers of under five aged children.

\section{METHODS}

A descriptive cross sectional study was conducted in child OPD of Friends of Shanta Bhawan in Jorpati, Boudha from March 8 to March 23, 2011. Approval was taken from the related Organization to collect the data. Informed verbal consent was from respondents before asking questions. The targeted population of the study was mother of children belonging aged under five attending child OPD and had taken OTC medicines during last 6 months for child. 100 sample size was calculated using the prevalence study formula. Face to face interview was conducted using structured questionnaire to collect the data about OTC. The questionnaire was pretested in $10 \%$ of sample attending child OPD at Friends of Santa Bhawan. The data was entered using Epi- data software and was analyzed by using SPSS 11.5 version. For the descriptive analysis, mean, median, frequency, percentage, standard deviation was calculated. 


\section{RESULTS}

Table 1: Socio Demographic of Respondents $(\mathrm{n}=100)$

\begin{tabular}{|c|c|c|}
\hline Descriptive & Frequency & Percent \\
\hline Age: : $17-25$ years & 40 & 40 \\
\hline 26-33 years & 48 & 48 \\
\hline $34-40$ years & 12 & 12 \\
\hline \multicolumn{3}{|l|}{ Religion: } \\
\hline Hindu & 46 & 46 \\
\hline Buddhist & 50 & 50 \\
\hline Muslim & 2 & 2 \\
\hline Christian & 2 & 2 \\
\hline \multicolumn{3}{|l|}{ Education status of mother: } \\
\hline Illiterate & 52 & 52 \\
\hline Primary & 18 & 15 \\
\hline Lower secondary & 12 & 12 \\
\hline Secondary & 13 & 13 \\
\hline Up to university & 5 & 5 \\
\hline \multicolumn{3}{|l|}{ Education status of father: } \\
\hline Illiterate & 21 & 21 \\
\hline Primary & 28 & 28 \\
\hline Lower secondary & 18 & 18 \\
\hline Secondary & 25 & 25 \\
\hline Up to university & 8 & 8 \\
\hline \multicolumn{3}{|l|}{ Occupation of mother: } \\
\hline Housewifc & 75 & 75 \\
\hline labor & 17 & 17 \\
\hline Business & 7 & 7 \\
\hline Services & 1 & 1 \\
\hline Occunation of father: & & 16 \\
\hline Business & 16 & 37 \\
\hline Services & 37 & 1 \\
\hline Agriculture & 1 & 46 \\
\hline labor & 46 & \\
\hline \multicolumn{3}{|l|}{ Types of family: } \\
\hline Nuclcar family & 83 & 83 \\
\hline Joint family & 17 & 17 \\
\hline \multicolumn{3}{|l|}{ Number of children : } \\
\hline One & 41 & 41 \\
\hline Two & 41 & 41 \\
\hline Three & 16 & 16 \\
\hline Four & 2 & 2 \\
\hline
\end{tabular}

The majority of the respondents ( $48 \%$ ) are in the age of 26 33 years, mean age of the respondents was 27.16. Majority of respondents were illiterate, Buddhist, housewife, belongs to nuclear family.

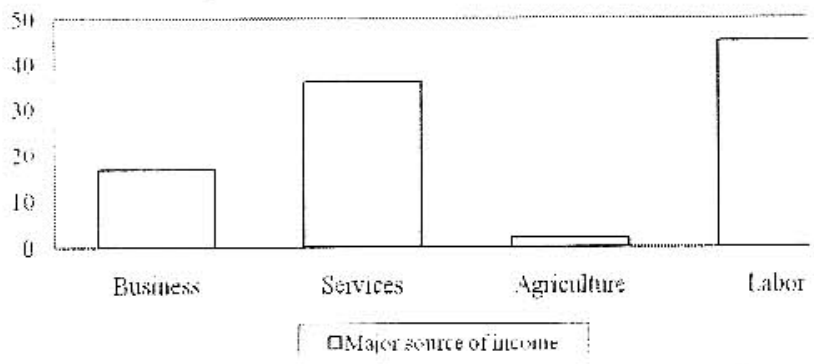

Figure 1: Major Source of Income of Respondents

Figure I shows that nearly half of the respondents' $(45 \%)$ major source of income was labor followed by services $36 \%$, business $17 \%$ and agriculture $2 \%$.

Nearly all respondents (93\%) used antipyretic, $75 \%$ used for cough syrup followed by $16 \%$ used anti-diarrheal as OTC medication for their under 5 years children.
Table 2: Reasons for Using OTC Medication $(n=100)$

\begin{tabular}{|c|c|c|}
\hline Description & Frequency & Pers \\
\hline $\begin{array}{l}\text { Reasons for using OTC medication: } \\
\text { Near from home } \\
\text { Suggested by athers } \\
\text { Easy to get } \\
\text { Low cost } \\
\text { Time saving } \\
\text { Believable }\end{array}$ & $\begin{array}{c}65 \\
1 \\
48 \\
9 \\
18 \\
23\end{array}$ & \\
\hline $\begin{array}{l}\text { Duration for using OTC medication } \\
\text { Till sign and symptoms subsides } \\
\text { For a day till visit to a doctor } \\
\text { For at least } 2 \text { days }\end{array}$ & $\begin{array}{l}90 \\
4 \\
6\end{array}$ & \\
\hline $\begin{array}{l}\text { Use of OTC medications are } \\
\text { influenced from } \\
\text { Self } \\
\text { Friends } \\
\text { Family }\end{array}$ & $\begin{array}{l}83 \\
13 \\
4\end{array}$ & \\
\hline $\begin{array}{l}\text { Relation with any health relatives: } \\
\text { Doctor/nurse/FCHV } \\
\text { No any }\end{array}$ & $\begin{array}{c}9 \\
91\end{array}$ & \\
\hline $\begin{array}{l}\text { Means of transportation for reaching } \\
\text { pharmacy } \\
\text { By foot }\end{array}$ & 100 & \\
\hline
\end{tabular}

Table 2 represent that among 100 respondents $65 \%$ used OTC medication for their children because it is near form home, $48 \%$ used it because it is easy to get and 18\% said that it is time saving than visit to doctors. $90 \%$ of respondent used the OTC medication for their children until the sign and symptoms subside. $83 \%$ of respondents influenced from OTC by themselves.

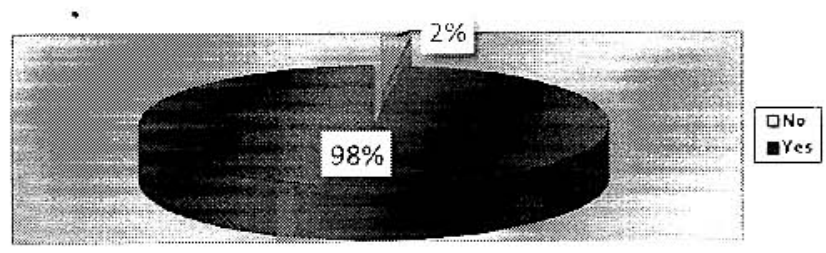

Figure 2: Information Regarding Dose and Frequency Provided by Pharmacist

Figure 2 shows that nearly all respondents $(98 \%)$ were provided with information regarding dose and frequency by pharmacist.

Among 100 respondents 73 were checked by pharmacist and among them 63 were checked for the temperature followed by 25 were checked for chest, 10 for ENT and only 1 for pulse.

\section{DISCUSSION}

The aim of the study was to assess the practice on OTC drug among mothers of under five aged children. In this study most of the mothers (93\%) used antipyretic, $75 \%$ used for cough syrup followed by $16 \%$ used anti-diarrheal as OTC medication for their under 5 years children. $65 \%$ who 
used OTC reasoned that their homes are near from pharmacy shops and $48 \%$ said that it is easy to get and time saving than to visit to doctors. Most of the mothers $90 \%$ used OTC medication till sign and symptoms subsided. The majority of the respondents $85 \%$ stayed within 30 minutes walking distance of hospitals.

Other study done in population of Czech Republic showed that they would buy OTC just on the basis of television advertising by $7 \%$ of respondents. In case for one year child $8 \%$ respondents opted for OTC. Study in Ghananian District showed that care givers of children under five age children out of 2006 household 529 indicated that longer travel, waiting and treatment times encourage people to use OTC medication. A study conducted in 1459 school children showed that $59.4 \%$ mother practices OTC for their children. ${ }^{6}$

Worldwide survey shows that $28 \%$ use OTC drugs. The use of many OTC medicines in children is usually initiated by parents in a study in which mothers of 8145 pre-school age children were interviewed, OTC medicines. It was reported that more than half of the children $(54 \%)$ were given an OTC medicines during past 30 days. The most common medication administered were analgesics, antipyretics and cough and cold medicines. ${ }^{7} \mathrm{~A}$ study conducted in a rural village in Philippines revealed that antibiotics are routinely given in self medication for non severe childhood diarrheal illness. ${ }^{4}$ A study carried out in brazillian village found that $50-66 \%$ uses antibiotics as an OTC medication for the children. ${ }^{5}$ cross sectional survey in 10 districts in Ulaanbaatar Mongolia's capital, using structured questionnaire 540 household with at least a child aged $<5$ years found that of 503 participants $42.3 \%$ used non prescribed antibiotics to treat symptoms in their child during previous 6 months. Symptoms commonly treated were cough (84\%), fever (66\%), nasal discharge (65\%), and sore throat $(60 \%)$. Amoxicillin was the most commonly used antibiotics $(58 \%)$.pharmacies were the main source $(86 \%)$ of no prescribed antibiotics. Non prescribed use by mother was significantly associated with keeping antibiotics at home. ${ }^{7}$

\section{CONCLUSION}

This study concluded that mothers used OTC for the common problems of their children because OTC medications are near to reach and easy to get than to visit to doctors or hospitals.

\section{REFERENCES}

1. The World Safe Medication Industry. Healthcare, Self care and Self medication, 14 National surveys reveal many similarities in consumer practices.WSMI 1988

2. Univezita Karlova V Praze et al. Knowledge, Attitude and Behavior of the Population of the Czech. Republic to the self medication.2005 Sep; 54950:211-8

3. PR Shankar,P Partha and N Sheony, Self medication and non doctor prescription practises in Pokhara Valley, western Nepal.BMC family practice.2002;3:17

4. Justice Nonvignon, Moses KS Aikins et all. Treatment Choices for Fever in Children Under five years in a rural Ghananian District. Malaria Journal; 28 June 2010, 9:188.

5. Hardon A.P. The Use of Modern Pharmaceutical in a Filipino Village. Doctors Prescription and selfmedication. Soc Sci Med. 2010; 1988; 27(2):1415-29.

6. Peng Bi, Shilu Tong and Kevin A ei al. Family self medication and antibiotics abuse for children and juveniles in a Chinese City. Social Science \& Medicine.2000; (50)10:1445-1450.

7. Allan E Shefrin. Use of OTC cough and cold medication in children. Canadian Family Physician Nov 2009; (55)11:1081-1083. 